\title{
Mitochondrial DNA 4977 BP deletion mutations in lung carcinoma
}

\author{
Ji Gang Dai, Ying Bin Xiao, Jia Xin Min, Guo Qiang Zhang, Ke Yao, Ren Jie Zhou \\ Department of Thoracic Cardiovascular Surgery of Xinqiao Hospital, The Third Military Medical \\ University, Chongqing - 400037, China.
}

Correspondence to: Xiao YB, E-mail: daijigangdaijigang@yahoo.co.nz

\section{Abstract}

BACKGROUND: The most common and also the most often assayed mtDNA deletion mutation, $\square m^{2} D N A^{4977}$ has been demonstrated in various types of human cancer. However, knowledge about $\square m t^{2} N A^{4977}$ in lung carcinoma is poor. AIM: To study the 4977 bp deletions of mitochondrial DNA ( $\square m_{t D N A}^{4977)}$ in lung cancer, adjacent histologically normal and normal lung tissue and its potential roles in the development of cancer. MATERIALS AND METHODS: Thirty-seven matched lung cancer/adjacent histologically normal and 20 histologically normal lung tissue samples in subjects without lung cancer were analyzed by PCR technique. RESULTS: $\square$ mtDNA ${ }^{4977}$ deletions were detected in $54.1 \%(20 / 37)$ of lung cancers, $59.5 \%$ (22/37) of adjacent normal and $30.0 \%(6 / 20)$ of normal lung tissue samples. No significant difference was found in the frequency of $\square \mathrm{mtDNA}^{4977}$ deletions between the tumor and adjacent normal lung tissues ( $P$ value $=0.815$ ). Moreover, no significant difference was found in the frequency of $\square \mathrm{mtDNA}^{4977}$ deletions between the tumor and histologically normal lung tissues in subjects without lung cancer $(P$ value $=$ 0.101). However, the correlation between $\square$ mtDNA $^{4977}$ deletion and age and smoking factors was present in our data. STATISTICAL ANALYSIS: Fisher's exact test was used to assess the difference in different groups by the Scientific Package for Social Sciences (SPSS), version 10.0, Statistical analysis software. CONCLUSINS: Mitochondrial DNA 4977 bp deletion, which is not specific to lung cancer, may reflect the environmental and aging process influences operative during tumor progression.

Key Words: Deletion, lung carcinoma, mitochondrial DNA, mutation

Mitochondria are the intracellular organelles responsible for adenosine triphosphate (ATP) synthesis through the coupling of oxidative phosphorylation (OXPHOS) to mitochondrial respiration in human and animal cells. They contain their own genome in the form of mitochondrial DNA (mtDNA), which is the only extrachromosomal DNA in human cells. Mitochondria are involved in apoptosis and probably also tumorigenesis, ${ }^{[1,2]}$ which has led researchers to examine the potential roles of mtDNA alterations in the development and maintenance of cancers. Mammalian mitochondrial DNA (mtDNA) is a circular doublestranded DNA of $16.5 \mathrm{~Kb}$ in size. In contrast to the nuclear DNA, mtDNA is a naked compact DNA molecule without introns and is replicated at a much higher rate without an efficient DNA repair mechanism.
Therefore, mtDNA is more vulnerable to attacks by reactive oxygen species and free radicals. Each nucleated human cell contains a few thousand copies of mtDNA, the somatic mutation rate of which is presumed to be 10 to 20 times higher than that of nuclear DNA. ${ }^{[3-5]}$

Human mitochondrial DNA (mtDNA) is becoming the study hotspot for its alteration in correlation with its tumorigenesis. ${ }^{[6]}$ mtDNA mutations were reported in different types of cancer and cancer cell lines. Reported sequence changes include point mutations (mostly transitions), multiple deletions and microsatellite instability in coding and noncoding regions. ${ }^{\text {7-11] }}$ Mitochondrial DNA 4977 bp deletion $\left(\Delta \mathrm{mtDNA}^{4977}\right)$ is the most common change in mtDNA and has been detected in several types of human tumors including 
gastric cancer, esophageal carcinoma, hepatocellular carcinoma, thyroid tumors, etc. ${ }^{[12-14]}$ However, little is known about this deletion of mtDNA in lung cancer. In this study, $\Delta$ mtDNA $^{4977}$ deletion mutation was detected in lung cancer, adjacent histologically normal and histologically normal lung tissue samples in subjects without lung cancer and the correlation between $\Delta \mathrm{mtDNA}^{4977}$ and age and smoking factors was analyzed.

\section{Materials and Methods}

\section{Subjects}

The following specimens were collected at our hospital from January 2003 to December 2003, including 37 matched lung cancer and adjacent histologically normal tissue samples and 20 normal lung tissues from patients without lung cancer. (STR typing was not done.) Patients with infectious diseases such as pneumonia, fungal infection and pulmonary tuberculosis; those with centrally located tumors with obstructing pneumonitis; and those who had received chemotherapy or radiotherapy for primary or metastatic lung malignancies were excluded from the study. None of the patients recruited into the study had a known history of industrial or occupational exposure to asbestos or organic solvent. All the tissues were kept in liquid nitrogen immediately after surgical resection according to a protocol, which were in accordance with the ethical standards of the responsible committee for conducting human research at the hospital and with the Helsinki Declaration of 1975, as revised in 2000. Smoking habit was classified into three categories: (1) current smokers, consisting of subjects who had smoked more than one cigarette or part thereof daily for more than $1 \mathrm{yr}$; (2) ex-smokers, consisting of subjects who had been previously reported as smokers and had quit smoking for more than $1 \mathrm{yr}$; and (3) nonsmokers, consisting of subjects who had never smoked. [Table 1] is a further description of the patient materials.

Total cellular DNA containing the mtDNA and nucleus DNA (nDNA) was prepared using the routine method: (1) Small amounts of tissue (100 mg) were snipped off, suspended in cell lysis buffer and incubated for $1 \mathrm{~h}$ at $37^{\circ} \mathrm{C}$. (2) The cell suspensions were mixed by vortexing and incubated for $3 \mathrm{~h}$ at $50^{\circ} \mathrm{C}$ after the addition of enzyme $\mathrm{K}(20 \mathrm{mg} / \mathrm{ml})$. (3) They were mixed by vortexing for $10 \mathrm{~min}$ and centrifuged at 5000 $\mathrm{r} / \mathrm{min}$ for $15 \mathrm{~min}$ at room temperature after the addition of equal volume of Tris-saturated phenol. (4) The aqueous fraction was extracted twice with an equal volume of phenol: chloroform: isopentanol $(25: 24: 1)$. (5) The aqueous fraction was preserved at $-20^{\circ} \mathrm{C}$ for 1 $h$ after the addition of 2 volume of ethanol and 0.1
Table 1: General information of the patients

\begin{tabular}{lccc} 
& $\begin{array}{c}\text { Cancer } \\
(\mathrm{n}=37)\end{array}$ & $\begin{array}{c}\text { Adjacent normal } \\
(\mathrm{n}=37)\end{array}$ & $\begin{array}{c}\text { Normal } \\
(\mathrm{n}=20)\end{array}$ \\
\hline Age (Median age) & $30 \sim 75(55)$ & $30 \sim 75(55)$ & $25-70(50)$ \\
\hline Sex & & & \\
\hline Female & 9 & 9 & 13 \\
\hline Males & 28 & 28 & 7 \\
\hline
\end{tabular}

Histological types

Squamous cell cancer 23

\begin{tabular}{lccc}
\hline Adenocarcinoma & 14 & & \\
\hline Smoking habit & & 15 & 9 \\
\hline Smokers & 15 & 9 & 4 \\
\hline Ex-smokers & 9 & 13 & 7
\end{tabular}

volume of $3 \mathrm{~mol} / \mathrm{L}$ sodium acetate. (6) Total DNA was collected as a pellet by centrifugation at $12000 \mathrm{r} / \mathrm{min}$ for $10 \mathrm{~min}$ at $4^{\circ} \mathrm{C}$. (7) DNA was washed once in $75 \%$ ethanol, collected by centrifugation at $12000 \mathrm{r} / \mathrm{min}$ for $5 \mathrm{~min}$ and dried at room temperature. (8) DNA was resuspended in TE $(10 \mathrm{mmol} / \mathrm{L}$ Tris- $\mathrm{HCl}, \mathrm{PH} 7.5,1$ $\mathrm{mmol} / \mathrm{L}$ EDTA) and stored at $-20^{\circ} \mathrm{C}$.

\section{Detection of mitochondrial common deletion}

The $\Delta \mathrm{mtDNA}^{4977}$ deletion was detected as described by Rogounovitch et al[15] with two sets of primers (P1/P2 and $\mathrm{P} 3 / \mathrm{P} 4)$, one giving a product only in wild-type DNA, the other only in DNA with the $\Delta \mathrm{mtDNA}^{4977}$ deletion. Primer sequences: P1, 5'-CTG AGC CTT TTA CCA CTC CAG-3' (nt 9500 nt 9520); P2,5'GGT GAT TGA TAC TCC TGA TGC GN3' (nt 9641 nt 9619); P3, 5'-CCC ACT GTA AAG CTA ACT TAG CAT TAA CCN3' (nt 8293 nt 8321); P4,5’-GGT TTC GAT GAT GTG GTC TTT GN3' (nt $13530 \sim$ nt 13509).

PCR reactions were carried out using TaKaRa PCR kit (TaKaRa, Japan) in a $50 \mu \mathrm{l}$ reaction volume with 200 ng DNA template, $2 \mathrm{U}$ TaKaRa Taq DNA polymerase (TaKaRa, Japan), $2.5 \mathrm{mmol} / \mathrm{L} \mathrm{MgCl} 2,250 \mu \mathrm{mol} / \mathrm{L}$ each dNTP and $0.5 \mu \mathrm{mol} / \mathrm{L}$ of each primer. After denaturation at $94^{\circ} \mathrm{C}$ for $30 \mathrm{~s}$, the reaction mixture was cycled 30 times at $94^{\circ} \mathrm{C}$ for $30 \mathrm{~s}, 59^{\circ} \mathrm{C}$ for $30 \mathrm{~s}$ and $72^{\circ} \mathrm{C}$ for $1 \mathrm{~min}$, finally extended at $72^{\circ} \mathrm{C}$ for $10 \mathrm{~min}$.

PCR products were analyzed by $1 \%$ agarose gel electrophoresis at $60 \mathrm{~V}$ (the buffer fluid was $1 \times$ TAE buffer). The electrophoresis gels were observed under ultraviolet and photographed. 


\section{Sequencing analysis}

To confirm that the fragments generated by PCR amplification with primers $\mathrm{P} 3 / \mathrm{P} 4$ were mtDNA in origin, these bands were recovered from agarose gels and submitted to PCR reamplification with the original set of primers. Reamplification products were purified and sequenced using the ABI Prism BigDye Terminator Cycle Sequencing Kit (Perkin-Elmer, Foster City, CA) and an ABI Prism 377 DNA Sequencer (Perkin-Elmer). Sequencing was performed in both strands using the original primers.

\section{Statistical analysis}

Fisher's exact test was used to assess the difference in different groups by the Scientific Package for Social Sciences (SPSS), version 10.0, Statistical analysis software. A value of P less than 0.05 was considered statistically significant.

\section{Results}

$\Delta \mathrm{mtDNA}^{4977}$ deletions in lung cancer, adjacent normal and histologically normal lung tissue samples in subjects without lung cancer.

The detection of $\Delta \mathrm{mtDNA}^{4977}$ between the origins of replication of light and heavy mtDNA strands was performed by PCR amplification with two sets of primers. To control the ability to PCR-amplify mtDNA, one primer pair $(\mathrm{Pl} / \mathrm{P} 2)$ localized inside of the region referred to as $\Delta \mathrm{mtDNA}^{4977}$ that amplified a 142 -bp amplicon corresponding to wild-type mtDNA was used as an amplification control. In case the 4977-bp deletion is present, a 262-bp PCR product is generated as determined by another pair of primers ( $\mathrm{P} 3 / \mathrm{P} 4)$ annealing to the fragments flanking the deleted region [Figure 1]. These bands were further sequenced and confirmed to be mitochondrial in origin. $\square \mathrm{mtDNA}^{4977}$ deletions were detected in $54.1 \%(20 / 37)$ of lung cancers, $59.5 \%(22 / 37)$ of adjacent normal and $30.0 \%$ $(6 / 30)$ of histologically normal lung tissues in subjects without lung cancer [Table 2]. No significant difference was found in the frequency of $\square$ mtDNA $^{4977}$ deletions between the tumor and adjacent normal lung tissues $(P$

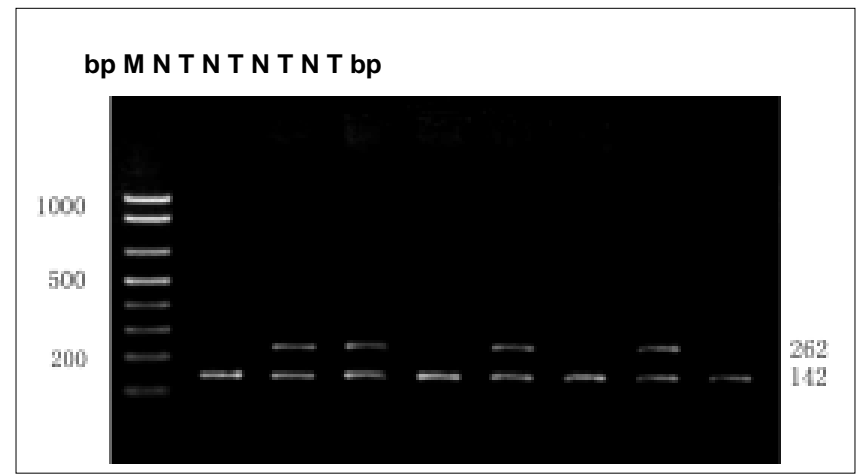

Figure 1: Detection of $\square$ mtDNA4977 in tumor and adjacent normal tissue

value $=0.815)$. The frequency of $\square \mathrm{mtDNA}^{4977}$ deletions in lung cancers and adjacent normal tissues appeared to be higher than that in histologically normal lung tissue samples in subjects without lung cancer. However, because of limited number of samples, no significant difference was found between the tumor and normal lung tissues $(P$ value $=0.101)$ and between adjacent normal and normal lung tissues $(P$ value $=$ $0.052)$.

The detection of $\square \mathrm{mtDNA}^{4977}$ was performed by PCR amplification with two sets of primers. One primer pair (P1/P2) yields a 142 bp amplicon. In case the 4977 bp deletion is present, a 262-bp PCR product is generated as determined by another pair of primers (P3/P4). 142 and 262 bp bands, suggesting the presence of heteroplasmy, were amplified in 4977 bp deleted mtDNA and only 142 bp band was observed in wild mtDNA with primer sets $\mathrm{P} 1 / \mathrm{P} 2$ and $\mathrm{P} 3 / \mathrm{P} 4$. T: lung cancer tissues, $\mathrm{N}$ : matched normal tissues, $\mathrm{M}$ : PCR Markers.

\section{Frequency of $\square \mathrm{mtDNA}^{4977}$ and the age of patients}

The frequency of $\square \mathrm{mtDNA}^{4977}$ deletions increased with age in lung cancer, adjacent histologically normal and normal lung tissue samples and the highest frequency (88.9\%) of it appeared in adjacent histologically normal tissue samples from the older patients ( $>65$ years of age). The frequency of $\square \mathrm{mtDNA}^{4977}$ deletions [Table 2] in tissue samples of the group over 55 years of age was

\begin{tabular}{|c|c|c|c|c|c|c|c|c|c|c|c|c|c|}
\hline \multirow[t]{2}{*}{ Age } & \multicolumn{3}{|c|}{ Lung cancer } & \multicolumn{3}{|c|}{ Adjacent normal } & \multicolumn{3}{|c|}{ Normal } & \multicolumn{3}{|c|}{ Total } & \multirow[b]{2}{*}{$P$ value } \\
\hline & + & - & $+(\%)$ & + & - & $+(\%)$ & + & - & $+(\%)$ & + & - & $+(\%)$ & \\
\hline$\geq 55$ & 14 & 5 & 73.7 & 15 & 4 & 78.9 & 5 & 4 & 55.6 & 34 & 13 & 72.3 & \\
\hline$<55$ & 6 & 12 & 33.3 & 7 & 11 & 38.9 & 1 & 10 & 9.1 & 14 & 33 & 37.8 & \\
\hline Total & 20 & 17 & 54.1 & 22 & 15 & 59.5 & 6 & 14 & 30.0 & 48 & 46 & & 0.000 \\
\hline
\end{tabular}

*obtained using the Fisher's exact test, + $\square$ mtDNA ${ }^{4977}$ deletion, - without deletion, + (\%) frequency of $\square$ mtDNA ${ }^{4977}$ deletion. 
found to be significantly higher than that in the group younger than 55 years of age $(P<0.001)$.

\section{Frequency of $\square$ mtDNA ${ }^{4977}$ and cigarette smoke}

The results suggested that cigarette smoke played an important role in the increase of $\square \mathrm{mtDNA}^{4977}$ in cancerous and normal tissues [Table 3]. The incidence of the $\square \mathrm{mtDNA}^{4977}$ in current smokers was significantly higher than in those of nonsmokers $(P=0.002)$. The incidence of the $\square \mathrm{mtDNA}^{4977}$ in ex-smokers (consisting of subjects who had been previously reported as smokers and had quit smoking for more than 1 year) was significantly higher than in those of nonsmokers $(P=0.009)$.

\section{Frequency of $\square$ mtDNA $^{4977}$ deletions and histologically type of lung cancer}

The $\square$ mtDNA $^{4977}$ deletions were detected in 16 of 23 squamous cell cancer and 4 of 14 adenocarcinoma samples [Table 4]. The incidence of the $\square \mathrm{mtDNA}^{4977}$ deletions in squamous cell cancers were significantly higher than in those of adenocarcinoma samples $(P=0.0154)$.

\section{Discussion}

The most common and also the most often assayed mtDNA deletion mutation, $\square \mathrm{mtDNA}^{4977}$ is a deletion that occurs between nucleotides 8470 and 13477 of the human mtDNA. It has been established as responsible for or associated with several human diseases, including ocular myopathy, Pearson's syndrome, diseases that progress with age. ${ }^{[16]}$ Slipped-strand mispairing (SSM), DNA damage and defective DNA repair are the causes producing $\square \mathrm{mtDNA}^{4977}$. The mispairing between two 13 bp direct repeats (positions 8 470-8 482 and 13 447-13 459) after a single-strand break caused by ROS or electron species produces fragment-deleted mtDNA.

The accumulation of somatic mtDNA mutations could contribute to the progression of mitochondrial diseases, the occurrence of various types of degenerative diseases and aging ${ }^{[17-19]}$ and could be
Table 4: The frequency of $\square$ mtDNA $^{4977}$ deletions and histologically type of lung cancer

\begin{tabular}{lcccc} 
Histologically type & + & - & $+(\%)$ & $P$ value \\
\hline Squamous cell cancer & 16 & 7 & 69.5 & \\
\hline Adenocarcinoma & 4 & 10 & 28.6 & 0.0154 \\
\hline Total & 20 & 17 & & \\
\hline
\end{tabular}

*obtained using the Fisher's exact test, $+\square \mathrm{mtDNA}^{4977}$ deletion, without deletion, + (\%) frequency of $\square$ mtDNA $^{4977}$ deletion

associated with external factors such as radiation and cigarette smoking. ${ }^{[20,21]}$ Cortopassi et al ${ }^{[22]}$ reported that mtDNA 4977 deletions accumulate in normal individuals during aging, particularly in postmitotic tissues such as muscle and brain. The $\square \mathrm{mtDNA}^{4977}$ deletions in human lung tissues were found to be related to smoking habit or lifetime cigarette consumption. ${ }^{[23]}$ Cigarette smoke is a complex mixture of more than 3800 compounds, including both free radicals in high concentrations and chemical compounds that readily react to form other reactive substances. ${ }^{[24]}$ The free radicals cause peroxidation of membrane lipids, accumulation of oxidized dysfunctional proteins and increased DNA damage. In a study of the level of $\square \mathrm{mtDNA}^{4977}$ in bronchoalveolar tissues from smokers and non smokers a seven-fold higher frequency of this deletion was found in smokers. ${ }^{[25]}$ In this study, 37 matched lung cancer/ adjacent histologically normal and 20 normal lung tissue samples from patients without lung cancer were analyzed by PCR technique and the results showed that the frequency of $\square \mathrm{mtDNA}^{4977}$ deletions is related to cigarette smoke and age. These data suggested that environmental and aging factors play an important role in the accumulation of $\mathrm{mtDNA}$ deletion mutations. The incidence of $\square \mathrm{mtDNA}^{4977}$ deletions in squamous cell cancers was higher than in those of adenocarcinoma samples. We suspected it may be just a reflection of the cigarette smoke influences operative during the accumulation of $\square \mathrm{mtDNA}^{4977}$, because the proportion $(19 / 23)$ of smokers (including current smokers and exsmokers) in patients with squamous cell cancer was higher than that $(5 / 14)$ of adenocarcinoma.

Table 3: The frequency of $\square \mathrm{mtDNA}^{4977}$ deletions and cigarette smoke

\begin{tabular}{|c|c|c|c|c|c|c|c|c|c|c|}
\hline & \multicolumn{3}{|c|}{ Lung } & \multicolumn{3}{|c|}{ Normal } & \multicolumn{3}{|c|}{ Total } & \multirow[b]{2}{*}{$P$ value ${ }^{*}$} \\
\hline & + & - & $+(\%)$ & + & - & $+(\%)$ & + & - & $+(\%)$ & \\
\hline Current smoker & 11 & 4 & 73.3 & 4 & 5 & 44.4 & 15 & 9 & 62.5 & $0.999^{a}$ \\
\hline Ex-smoker & 6 & 3 & 66.7 & 2 & 2 & 50.0 & 8 & 5 & 61.5 & $0.009^{b}$ \\
\hline Nonsmoker & 3 & 10 & 23.1 & 0 & 7 & 0 & 3 & 17 & 15.0 & $0.002^{c}$ \\
\hline
\end{tabular}

*Obtained using the Fisher's exact test, $+\square \mathrm{mtDNA}^{4977}$ deletion, - without deletion, + (\%) frequency of $\square \mathrm{mtDNA}^{4977}$ deletion.a: smoker comparative to

Ex-smoker, b: Ex-smoker comparative to nonsmoker, c: Smoker comparative to nonsmoker. 
Carcinogenesis is a multi-step process involving the accumulation of genetic changes that end in malignant cell transformation. Contribution of mtDNA mutations to carcinogenesis was postulated when wide spectra of the mtDNA alterations were reported in different types of cancers: colon, lung, pancreatic, liver, thyroid, bladder, prostate, esophageal and gastric cancer. ${ }^{[7-11]}$ Cavalli et al[26] reported that the tumor cells were depleted of mitochondrial DNA by treatment with ethidium bromide. These rho(-) respiratory-deficient cells showed a distinct change in the tumorigenic phenotype, including loss of ability to grow in an anchorage-independent fashion and a substantial increase in sensitivity to cytotoxic drugs. Their results indicate that mitochondria/mitochondrial DNA play a direct role in modulating aspects of the tumorigenic phenotype. However, the biological impact of $\square \mathrm{mtDNA}^{4977}$ deletion on tumors is not entirely clear. Zhu et al[27] found that the $\square \mathrm{mtDNA}^{4977}$ was present in $33 \%$ of adjacent histologically normal specimens from a cancerous breast and $46 \%$ of breast cancers. The 4977 bp mtDNA deletion was detected in 12 of $13(92.3 \%)$ gastric tumor cell lines, 38 of 52 (73.1\%) of gastric tumors and 27 of $52(52 \%)$ adjacent normal tissues and was thought to play an important role in the carcinogenesis of human gastric tumor by Shen et $a l^{[28]}$ In this investigation, we found that $\square \mathrm{mtDNA}^{4977}$ was present in lung cancer, adjacent histologically normal and normal lung tissue samples and in eight cases of patients, the deletion was found in adjacent nontumoral tissues but not in cancerous tissues. These results suggest that $\square \mathrm{mtDNA}^{4977}$ deletion is not specific mutation to lung cancer.

The $\square$ mtDNA 4977 - which affects important genes involved in OXPHOS, such as ATPase 6, ATPase 8, cytochrome oxidase III, NADH subunits ND3, ND4, ND4L and ND5 and 5 of 22 tRNAs that are essential for protein synthesis of the mitochondria, may have a strong metabolic disadvantage so that cells carrying this mutation are selected against. Since each cell contains many mitochondria with multiple copies of mtDNA, it is possible that wild-type and mutant mtDNA can coexist in a state called heteroplasmy. The mtDNA deletions accumulated in cells may result in impaired mitochondrial respiration and decreased ATP synthesis and the cells harboring high proportion of mtDNA deletions may not survive and lead to dropout from the population. Dani et al considered ${ }^{[29]}$ that though the metabolic effect of mtDNA 4977 deletion may be minimal in tissue, in tissue with active cell division, such as in tumors, even low levels of $\square \mathrm{mtDNA}^{4977}$ deletions may be intolerable. One could argue that tumor cells have a higher capacity for glycolysis and do not rely entirely on OXPHOS to survive and hence that mutations such as $\square$ mtDNA $^{4977}$ deletion would not be metabolically detrimental. Nevertheless, the evidence ${ }^{[30-32]}$ indicates that, as glycolysis, OXPHOS is important to the survival and growth of tumors so that the cells harboring high proportion of mtDNA deletions cannot survive and lead to dropout from the population. "mtDNA4977 deletions were detected by Dani et al[33] in $24 \%$ of the breast tumors, $52 \%$ of the colorectal tumors, $79 \%$ of the gastric tumors and $40 \%$ of the head and neck tumors as compared with 77, 83, 100 and $90 \%$ of the adjacent respective nontumoral tissues. Real-time Quantitative PCR experiments were further performed to quantify the number of "mtDNA4977 deletions per cell in selective nine cases of cancers, by determining the mitochondrial-to-nuclear DNA ratio. The average number (303.32) of deletions/cell of "mtDNA4977 in tumors was also found to be significantly lower than that (6.73) of the respective nontumoral tissue. Our data support a prior report ${ }^{[34]}$ indicating that the 4977 bp deletion is present at similar frequency in both normal and tumor tissue. Therefore, we conclude that $3 \% \mathrm{mtDNA}^{4977}$ deletion, which is not specific to lung cancer, may reflect the environmental and aging-process influences operative during lung cancer progression. As regards whether this deletion mutation is directly associated with the development and progression of lung cancer is still unclear and was not the purpose of our current study but is an area which we plan to investigate in the future.

\section{References}

1. Green DR, Reed JC. Mitochondria and apoptosis. Science 1998;281:1309-12

2. Tang L, Zhang Y. Mitochondria are the primary target in isothiocyanate-induced apoptosis in human bladder cancer cells. Mol Cancer Ther 2005;4:1250-9.

3. Howell N, Kubacka I, Mackey DA. How rapidly does the human mitochondrial genome evolve? Am J Hum Genet 1996;59:501-9.

4. Taylor RW, Turnbull DM. Mitochondrial DNA mutations in human disease. Nat Rev Genet 2005;6:389-402.

5. Parsons TJ, Muniec DS, Sullivan K, Woodyatt N, Alliston-Greiner $\mathrm{R}$, Wilson MR, et al. A high observed substitution rate in the human mitochondrial DNA control region. Nat Genet 1997;15:363-8.

6. Cavalli LR, Liang BC. Mutagenesis, tumorigenicity and apoptosis:are the mitochondria involved? Mutat Res 1998;398: 1926.

7. Czarnecka AM, Golik P, Bartnik E. Mitochondrial DNA mutations in human neoplasia. J Appl Genet 2006;47:67-78.

8. Maitra A, Cohen Y, Gillespie SE, Mambo E, Fukushima N, Hoque MO, et al. The Human MitoChip: A high-throughput sequencing micro array for mitochondrial mutation detection. Genome Res 2004; 14:812-9.

9. Frenny VJ, Antonella Z, Luisa A, Shah AD, Sheth JJ, Rocchi M. Cytogenetics and fluorescence in-situ hybridization in detection of hematological malignancies. Indian J Cancer 2003;40: 135-9.

10. Dai JG, Min JX, Zhang GQ. The study on mitochondrial DNA 
Mutations in mouse tumors. Zhong Hua Bing Li Xue Za Zhi 2004; 13:458-61.

11. Fliss $M K$, Usadel $\mathrm{H}$, Cabellero $\mathrm{OL}$. Facile detection of mitochondrial DNA mutations in tumors and bodily fluids. Science 2000;287:2017-9.

12. Wu CW, Yin PH, Hung WY, Li AF, Li SH, Chi CW, et al. Mitochondrial DNA mutations and mitochondrial DNA depletion in gastric cancer. Genes Chromosomes Cancer 2005;44:19-28.

13. Abnet CC, Huppi K, Carrera A, Armistead D, McKenney K, Hu N, et al. Control region mutations and the 'common deletion' are frequent in the mitochondrial DNA of patients with esophageal squamous cell carcinoma. BMC Cancer 2004;1;4-30.

14. Maximo V, Soares P, Lima J, Cameselle-Teijeiro J, Sobrinho-Simoes M. Mitochondrial DNA somatic mutations (point mutations and large deletions) and mitochondrial DNA variants in human thyroid pathology: A study with emphasis on Hurthle cell tumors. Am J Pathol 2002; 160:1857-65.

15. Rogounovitch TI, Saenko VA, Shimizu-Yoshida Y, Abrosimov AY, Lushnikov EF, Roumiantsev PO, et al. Large Deletions in Mitochondrial DNA in Radiation-associated Human Thyroid Tumors. Cancer Research 2002;62:7031-41.

16. Crott JW, Choi SW, Branda RF, Mason JB. Accumulation of mitochondrial DNA deletions is age, tissue and folate-dependent in rats. Mutat Res 2005;570:63-70.

17. Linnane AW, Marzuki S, Ozawa T, Tanaka M. Mitochondrial DNA mutations as an important contributor to ageing and degenerative diseases. Lancet 1989;1:642-5.

18. Wei $Y$ H. Mitochondrial DNA alterations as ageing associated molecular events. Mutat Res 1992;275:145-55.

19. Wei Y H. Oxidative stress and mitochondrial DNA mutations in human aging. Proc Soc Exp Biol Med 1998;217:53-63.

20. Pang CY, Lee HC, Yang JH, Wei YH. Human skin mitochondrial DNA deletions associated with light exposure. Arch Biochem Biophys 1994;312:534-8.

21. Lee HC, Lim ML, Lu CY, Liu VW, Fahn HJ, Zhang C, et al. Concurrent increase of oxidative DNA damage and lipid peroxidation together with mitochondrial DNA mutation in human lung tissues during aging-smoking enhances oxidative stress on the aged tissues. Arch Biochem Biophys 1999;362:309-16.

22. Cortopassi GA, Arnheim N. Detection of a specific mitochondrial DNA deletion in tissues of older individuals. Nucleic Acids Res
1990; 18:6927-33.

23. Fahn HJ, Wang LS, Kao SH, Chang SC, Huang MH, Wei YH. Smoking-associated mitochondrial DNA mutations and lipid peroxidation in human lung tissues. Am J Respir Cell Mol Biol 1998; 19:901-9.

24. Pakhale SS, Jayant K, Bhide SV. Total particulate matter and nicotine in Indian bidis and cigarettes:a comparative study of standard machine estimates and exposure levels in smokers in Bombay. Indian J Cancer 1989;26:227-32.

25. Ballinger SW, Bouder TG, Davis GS, Judice SA, Nicklas JA, Albertini RJ. Mitochondrial genome damage associated with cigarette smoking. Cancer Res 1996;56:5692-7.

26. Cavalli, LR, Varella-Garcia M, Liang BC. Diminished tumorigenic phenotype after depletion of mitochondrial DNA. Cell Growth Differ 1997;8:1189-98.

27. Zhu W, Qin W, Edward ER. Large-scale mitochondrial DNA deletion mutations and nuclear genome instability in human breast cancer. Cancer Detect Prevent 2004;28:119-26.

28. Shen H, Zhao M, Dong B, Tang W, Xiao B, Liu JZ, et al. Frequent 4 977 bp deletion of mitochondrial DNA in tunlor cell lines, solid tumors and precancerous lesions of human stomach. Zhonghua Yi Xue Za Zhi 2003;83:1484-9.

29. Dani SU, Dani MA, Simpson AJ. The common mitochondrial DNA deletion detamt DNA (4977) : Shedding new light to the concept of a tunmor suppressor mutation. Med Hypotheses 2003;61:603.

30. Hayashi JI, Takemitsu M, Nonaka I. Recovery of the missing tumorigenicity in mitochondrial DNA-less HeLa cells by introduction of mitochondrial DNA from normal human cells. Somat Cell Mol Genet 1992;18:123-9.

31. Israel BA, Schaeffer WI. Cytoplasmic suppression of malignancy. In Vitro Cell Dev Biol 1987;23:627-32.

32. Israel BA, Schaeffer WI. Cytoplasmic mediation of malignancy. In Vitro Cell Dev Biol 1988,24:487-97.

33. Dani MA, Dani SU, Lima SP, Martinez A, Rossi BM, Soares F, et al. Less mtDNA4977 than normal in various types of tumors suggests that cancer cells are essentially free of this mutation. Genet Mol Res 2004;3:395-409.

34. Bianchi MS, Bianchi NO, Bailliet G. Mitochondrial DNA mutations in normal and tumor tissues from breast cancer patients. Cytogenet Cell Genet 1995;71:99-103. 